\title{
Evaluation of glycine betaine as an inhibitor of dissolved dimethylsulfoniopropionate degradation in coastal waters
}

\author{
Ronald P. Kiene*, Ghislain Gerard \\ Department of Marine Sciences, University of South Alabama, LSCB 25, Mobile, Alabama 36688, USA \\ and
}

Marine Environmental Sciences Consortium, Dauphin Island Sea Lab, Dauphin Island, Alabama 36543, USA

\begin{abstract}
Dimethylsulfoniopropionate (DMSP) is an organic sulfur compound which is produced by many marine phytoplankton and which is ubiquitous in the euphotic zone of the ocean. DMSP is degraded through complex interactions within the food web and studies of its dynamics may lead to greater understanding of microbial ecology and food web interactions. In this study we examined the degradation of dissolved DMSP [DMSP(d)] in coastal water samples and tested glycine betaine (GBT), a structural analog of DMSP, as a potential inhibitor of this important biogeochemical reaction. The addition of 1 to $50 \mu \mathrm{M}$ GBT to water samples from the northern Gulf of Mexico strongly inhibited the consumption of $50 \mathrm{nM}$ added DMSP(d). The production of dimethyl sulfide (DMS) from DMSP(d) was also inhibited by GBT, but was slightly less sensitive than overall DMSP degradation. The inhibitory effects of GBT were short-lived, lasting only 5 to $6 \mathrm{~h}$, after which time net DMSP(d) consumption resumed. Several analogs of GBT were also found to be inhibitory to DMSP(d) degradation but unrelated compounds had no effects. Consistent with the inhibitory effects of GBT, we found that endogenous DMSP(d) concentrations increased at steady rates in response to GBT additions. These GBT-induced accumulation rates ranged from 4 to $28 \mathrm{nM} \mathrm{d}^{-1}$ in water samples collected over the course of a year and may represent the natural turnover rates of DMSP(d). We found no significant effects of GBT on particulate DMSP concentrations in natural water samples or in an axenic culture of the prasinophyte Tetraselmis subcordiformis. However, addition of $50 \mu \mathrm{M}$ GBT to the phytoplankton culture caused an accumulation of DMSP(d) (equivalent to $2 \%$ of the particulate DMSP in the culture) for a period of $1 \mathrm{~h}$ with no change thereafter. GBT may be a useful inhibitor of DMSP(d) degradation (and DMS production) under some circumstances. However, the short-lived inhibitory effects of GBT and the potential for it to cause some direct release from the particulate DMSP pool may limit its application.
\end{abstract}

KEY WORDS: Dimethylsulfide - Tertiary sulfonium - Quaternary ammonium . Climate - Biogeochemistry - Inhibition - Demethylation - Lyase

\section{INTRODUCTION}

Dimethylsulfoniopropionate (DMSP) is an organic sulfur compound which is ubiquitous in photic waters of the marine environment (Turner et al. 1988, Iverson et al. 1989, Burgermeister et al. 1990). DMSP production in the water column is attributed to phytoplankton and macroalgae (White 1982, Reed 1983, Keller et al. 1989), though it may be found in other organisms due

\footnotetext{
•E-mail: rkiene@jaguar1.usouthal.edu
}

to trophic transfer and retention (Ackman \& Hingley 1968, Tokunaga et al. 1977, Iida \& Tokunaga 1986, Iida et al. 1986, Levasseur et al. 1994). The distribution and abundance of certain phytoplankton species strongly influences the concentration of DMSP in surface waters because only selected species produce large amounts of this osmotic solute (White 1982, Keller et al 1989, Keller 1991).

Interest in the marine biogeochemistry of DMSP and its degradation product, dimethylsulfide (DMS), has grown substantially in recent years because it is now recognized that DMS is the principal form of volatile 
sulfur in the surface ocean (Lovelock et al, 1972, Andreae \& Raemdonck 1983, Andreae 1990). DMS emissions from the ocean contribute nearly half of the global biogenic sulfur emission to the atmosphere (Andreae 1990) and may also play a role in modulating global climate through a cloud albedo mechanism (Bates et al. 1987, Charlson et al. 1987, Malin et al. 1992). Despite recent advances in DMS-related research, the mechanisms leading to DMS formation and the controls on its sources and sinks are not well understood.

Degradation of DMSP appears to be the main source of DMS in seawater, although not all DMSP is degraded to DMS (Belviso et al. 1990, Kiene \& Service 1991). DMSP release and degradation, as well as the production of DMS, are closely linked with food web activities (Dacey \& Wakeham 1986, Belviso et al. 1990, Gabric et al. 1993, Kiene 1993, Wolfe et al. 1994) Bacterial degradation of the dissolved DMSP pool [DMSP(d)] (operationally defined as that which passes a GF/F or $0.2 \mu \mathrm{m}$ filter) is thought to be a major pathway leading to DMS formation (Turner et al. 1988 Kiene 1990, Kiene \& Service 1991). The concentrations of DMSP(d) are generally in the low $\mathrm{nM}$ range in surface waters (Turner et al. 1988) and tend to be lower than the particulate pool of DMSP [DMSP(p)].

In addition to its role as a precursor of DMS, DMSP may represent a potentially important carbon substrate for bacterial populations in the marine environment. DMSP-carbon may comprise as much as 1 to $10 \%$ of the carbon in living phytoplankton (Kiene 1993, Bates et al. 1994, Matrai \& Keller 1994) and it is therefore not surprising that the ability to degrade DMSP is widespread among marine aerobic bacteria (Visscher et al. 1992, Ledyard \& Dacey 1994). At least 2 functional groups of bacteria are responsible for degrading DMSP in seawater: those which cleave DMSP into DMS and acrylic acid and those which demethylate DMSP to 3-methiolpropionate (Taylor \& Gilchrist 1991, Diaz et al. 1992, Visscher et al. 1992, Ledyard \& Dacey 1994, Visscher \& Taylor 1994)

To date, there have been no studies reporting DMSP(d) turnover rates at in situ concentrations in the water column. Progress in this area has been hampered by the limited availability of appropriate radiotracers and lack of effective inhibitors of this process for use in biogeochemical studies. Kiene \& Service (1993) recently presented evidence that DMSP(d) degradation in seawater samples was partially inhibited by the addition of $500 \mathrm{nM}$ glycine betaine (GBT), a naturally occurring structural analog of DMSP which is widespread in the marine environment (King 1988). The possibility that GBT could inhibit DMSP degradation was noteworthy since the enzymatic degradation of DMSP in water samples has proved to be insensitive to a variety of biological poisons including chloroform, azide, and antibiotics (Kiene 1990). Therefore, a detailed investigation of the effects of GBT and related compounds on DMSP degradation was carried out, with the overall aim being to learn more about the degradation of DMSP in natural systems

\section{MATERIALS AND METHODS}

Sample collection and processing. Most water samples used during this study were collected from a pier on the east end of Dauphin Island, Alabama, USA. This site is located in the northern Gulf of Mexico near the mouth of Mobile Bay $\left(30^{\circ} 20^{\prime} \mathrm{N}, 88^{\circ} 10^{\prime} \mathrm{W}\right.$ ). In several cases, water was collected from a boat approximately $10 \mathrm{~km}$ out from the mouth of Mobile Bay at a site termed the Sea Buoy. Water from this location was generally higher in salinity and lower in suspended solids than the Mobile Bay water. Samples were collected by bucket or carboy and dispensed immediately into 11 or $250 \mathrm{ml}$ Teflon bottles. Water samples were stored in the dark and returned to the laboratory within $1 \mathrm{~h}$ where they were used immediately for experimental incubations. During the incubations, the bottles were maintained within $1^{\circ} \mathrm{C}$ of in situ temperature and kept in the dark, except during subsampling ( $<2$ min duration) when they were exposed to room light. The water samples were not shaken during the incubations, but were gently inverted several times before subsamples were removed for sulfur compound analysis.

Experimental design. The concentrations of DMSP(d), DMSP(p) and DMS were monitored in water samples over time courses which lasted from 5 to $30 \mathrm{~h}$. In experiments designed to test the effects of GBT and related compounds on DMSP(d) consumption, spike additions of 40 to $50 \mathrm{nM}$ (final concentration) of DMSP were made to water samples just after the addition of the compound to be tested. The first subsample for measurement of DMSP(d) was taken within 2 min of the addition and this time point was designated as time zero. Also included in all experiments of this type were samples which received DMSP(d) alone (i.e no inhibitor) and those which received no addition. Because the consumption kinetics for DMSP(d) were fast (see 'Results'), and a rapid sampling schedule needed to be maintained, most experiments included single bottles for each treatment. Duplicate treatments were occasionally run and replication for DMS and DMSP(d) measurements was usually better than $10 \%$

A series of experiments were carried out to test the ef fects of GBT and some structural analogs on DMSP(d) degradation in seawater samples. GBT was evaluated most extensively and was used at concentrations ranging from 0.05 to $50 \mu \mathrm{M}$. This represented 1 to $1000 \times$ the 
concentration of added DMSP in the experiments. The analogs tested included $\beta$-alanine betaine $\mathrm{HCl}$, choline. $\mathrm{HCl}$, dimethylglycine, carnitine, proline, diethylsulfoniopropionate. $\mathrm{HCl}$ (DESP), and choline-O-sulfate. To complement these experiments, several non-onium compounds were also tested, including glucose, glycine, glutamic acid and acrylic acid. The rates of net DMSP consumption and DMS production in samples treated with potential inhibitors were compared to the rates in samples without inhibitors. The results are presented as percent inhibition and were calculated as follows: $\%$ inhibition $=[1-($ rate in inhibitor-treated samples/rate in DMSP only samples) $] \times 100$

In experiments designed to test the effects of GBT on endogenous pools of DMSP(d), $50 \mu \mathrm{M}$ GBT was added to natural water samples at the start of the incubation and DMSP(d) was monitored over time. Linear regression equations were fit to the DMSP(d) time course data and the net accumulation rate was estimated as the difference between the slopes in GBT-treated and untreated samples.

Several experiments focused specifically on the effects of $50 \mu \mathrm{M}$ GBT on particulate DMSP pools in natural water samples incubated in the dark. GBT was added to duplicate or triplicate freshly collected water samples and DMSP(p) monitored over a 0 to $6 \mathrm{~h}$ time course. A similar experiment was carried out with an axenic culture of the DMSP-producing phytoplankter Tetraselmis subcordiformis which was grown in $500 \mathrm{ml}$ of Guillard's $\mathrm{F} / 2$ medium (Sigma) on a 12/12 h light/dark cycle. The culture was used while cells were in log phase growth and additions of $50 \mu \mathrm{M} \mathrm{GBT}$ were made to duplicate 100 $\mathrm{ml}$ cultures. Untreated control cultures were also used and samples were taken for DMSP(d) and DMSP(p) analysis over a $6 \mathrm{~h}$ period after GBT addition.

Analytical methods. DMS and DMSP(p) were measured by gas chromatography as described previously (Kiene \& Service 1991). The procedure for DMSP(d) analysis was modified somewhat from that used previously. A $20 \mathrm{ml}$ subsample was removed from the incubation bottle and allowed to drip through a $47 \mathrm{~mm}$ Gelman AE filter held in a glass filter tower. The filter was used for DMSP(p) determinations while the filtrate was used for DMSP(d) determinations. After all of the sample had passed the filter, approximately $5 \mathrm{ml}$ of the filtrate was placed in a small open sparge tube and bubbled with He $\left(100 \mathrm{ml} \mathrm{min}^{-1}\right.$ for $\left.2 \mathrm{~min}\right)$ to remove DMS. After the He flow was turned off, $1 \mathrm{ml}$ of the sample was removed by pipette and placed in a $14 \mathrm{ml}$ serum vial. One ml of $5 \mathrm{~N} \mathrm{NaOH}$ was added to this vial and it was sealed quickly with a Teflon-faced butyl rubber septum. DMSP in the water sample was decomposed quantitatively to DMS (and acrylic acid) by the $\mathrm{NaOH}$. After $30 \mathrm{~min}$, the reaction was complete and the sample could be analyzed, although the sample was routinely analyzed the next day $(<24 \mathrm{~h}$ ). The DMS in the vials was measured by sweeping the headspaces of the serum vials into a cryotrap and subsequently into a gas chromatograph as described in Kiene \& Gerard (1994) Standards were prepared using the same liquid volumes as the samples. This approach yielded excellent precision (typically better than $5 \%$ ) and low detection limits $(0.5$ to $1.0 \mathrm{nM})$ for $1 \mathrm{ml}$ samples.

Terminology. We measured the decrease of DMSP(d) concentrations over time courses and we refer to this as net consumption or degradation. We know that the added DMSP(d) was degraded (as opposed to sequestered into particulate material) because particulate DMSP concentrations always held steady or declined slightly during the incubations which were carried out in the dark. We refer to exogenous DMSP(d) as that which we added to the water samples, usually 30 to $50 \mathrm{nM}$. Endogenous DMSP(d) refers to that which is naturally present in the water samples.

Chemicals. DMSP.HCl was obtained from Research Plus, Inc., and was used from concentrated stocks which were kept frozen. GBT was obtained from Sigma in either the hydrochloride or anhydrous form. No discernible differences in effects on DMSP were observed between these 2 chemical forms of GBT Choline-O-sulfate and $\beta$-alanine betaine-HCl were kind gifts from Dr Andrew Hanson. Diethylsulfoniopropionate.HCl was generously provided by Dr Barrie Taylor. All other chemicals were obtained from Sigma and were of the highest purity available.

\section{RESULTS}

\section{GBT inhibition of DMSP degradation}

The consumption of exogenous DMSP(d) in water samples from the mouth of Mobile Bay was rapid and usually displayed apparent first order kinetics (Fig. 1A). Net consumption of the added DMSP(d) was substantially inhibited ( $>84 \%$ inhibition) when water samples were treated with 1 to $50 \mu \mathrm{M}$ GBT (Fig. 1A). During the first $3 \mathrm{~h}$ of the incubation, each of the GBT treatment levels appeared to be equally effective at inhibiting DMSP consumption but by the end of the experiment (5.5 h), DMSP(d) had declined to a greater extent in the $1 \mu \mathrm{M}$ treatment. Net DMS production was also inhibited by GBT, with a greater inhibition at higher GBT concentrations (Fig. 1B). GBT appeared to increase the yield of DMS [calculated as a percentage from the increase in DMS divided by the decrease in DMSP(d) over a given time intervall from 16 to $17 \%$ in the sample without GBT to $20-44 \%$ in those with GBT (Table 1). The increase in yield was most noticeable over the early part of the incubation ( 0 to $3 \mathrm{~h}$ ) as com- 
Table 1. Effects of several concentrations of glycine betaine (GBT) on the percentage yield of DMS during degradation of $40 \mathrm{nM}$ dissolved DMSP in Mobile Bay water samples. Results for 2 difterent time intervals are presented (0 to 3 h and 0 to $5.5 \mathrm{~h}$ ). GBT was inhibitory to DMSP degradation over this period (see Fig. 1 for time courses of DMSP and DMS). Percentage yield is defined as [maximum net accumulation of DMS/loss of DMSP(d) during the time interval] $\times 100$. Particulate DMSP pools did not change significantly during the incubation and averaged $100 \mathrm{nM}$

\begin{tabular}{|c|c|c|c|c|c|c|}
\hline Treatment & $\begin{array}{l}\text { hange in DMSP(d) } \\
\text { over } 3 \mathrm{~h}(\mathrm{nM})\end{array}$ & $\begin{array}{l}\text { Change in DMS } \\
\text { over } 3 \mathrm{~h}(\mathrm{nM})\end{array}$ & $\begin{array}{l}\% \text { yield of } \\
\text { DMS }(3 h)\end{array}$ & $\begin{array}{l}\text { Change in DMSP(d) } \\
\text { over } 5.5 \mathrm{~h}(\mathrm{nM})\end{array}$ & $\begin{array}{l}\text { Change in DMS } \\
\text { over } 5.5 \mathrm{~h}(\mathrm{nM})\end{array}$ & $\begin{array}{l}\% \text { yield of } \\
\text { DMS (5.5h) }\end{array}$ \\
\hline NT & -1.3 & -0.04 & - & -1.2 & -0.1 & - \\
\hline DMSP (50 nM) & -28.5 & +4.8 & 16.9 & -39.6 & +6.3 & 15.9 \\
\hline $\mathrm{DMSP}+50 \mu \mathrm{M}$ GBT & -3.1 & +0.9 & 29 & -9.6 & +2.1 & 21.9 \\
\hline DMSP + $10 \mu \mathrm{M}$ GBT & -3.4 & +1.3 & 38 & -12.5 & +2.8 & 22.4 \\
\hline DMSP + $1 \mu \mathrm{M}$ GBT & -5.0 & +2.2 & 44.0 & -21.9 & +4.4 & 20.1 \\
\hline
\end{tabular}
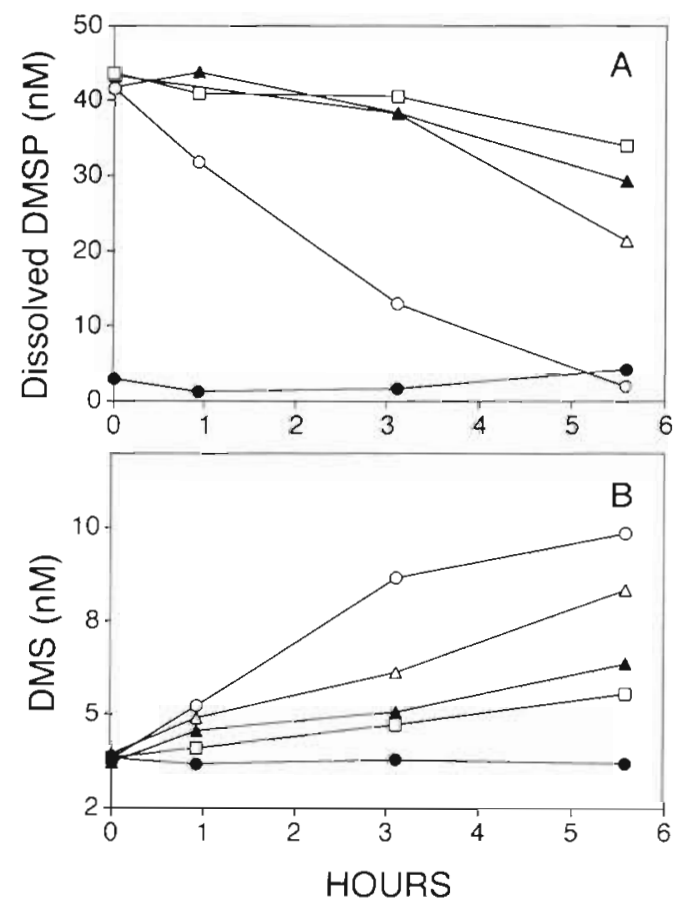

Fig 1. Time courses of (A) DMSP(d) and (B) DMS concentrations in water samples from Mobile Bay after the following treatments: no addition $(\bullet)_{i}+$ DMSP $(0)_{i}+$ DMSP $+1 \mu \mathrm{M}$ GBT $(\Delta)_{i}+\mathrm{DMSP}+10 \mu \mathrm{M} \mathrm{GBT}(\mathbf{\Lambda}) ;+\mathrm{DMSP}+50 \mu \mathrm{M} \mathrm{GBT}$ (a). Results are from single bottles for each treatment. Salinity of the water was 20 psu and temperature was $25^{\circ} \mathrm{C}$

pared to the full incubation period ( 0 to $5.5 \mathrm{~h})$. This difference suggests that DMS production was less sensitive to GBT than overall net DMSP(d) consumption. In separate experiments, we have found that concentrations of GBT as low as $50 \mathrm{nM}$ were inhibitory to DMSP $(d)$ consumption and DMS production, however, at these low GBT concentrations the effects were very short-lived $(<1 \mathrm{~h}$ ). Incubations carried out beyond 6 to $8 \mathrm{~h}$ showed that the inhibitory effects of $50 \mu \mathrm{M}$ GBT diminished considerably over time, and by 24 to $30 \mathrm{~h}$ the added DMSP(d) had often declined to the concentrations seen in controls (Fig. 2).

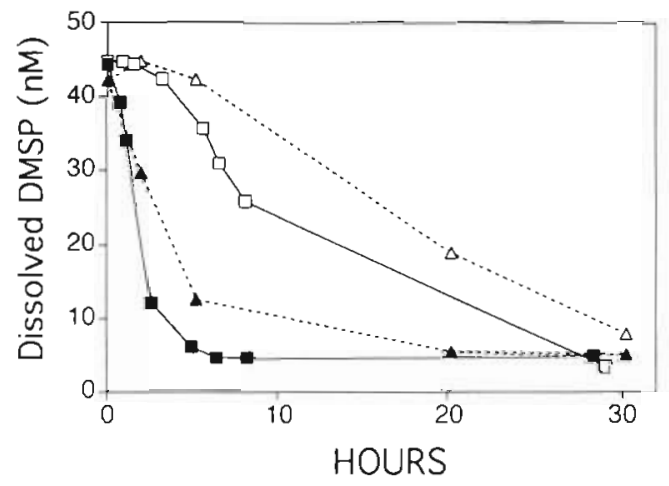

Fig. 2. Effects of $50 \mu \mathrm{M}$ GBT on DMSP(d) consumption during prolonged $(30 \mathrm{~h})$ incubations. Results from 2 separate experiments, July $6(\square, \boldsymbol{a})$ and July $19,1994,(\Delta, \Delta)$ are shown. Solid symbols represent samples treated with DMSP only, whereas the open symbols represent samples which received both DMS and $50 \mu \mathrm{M}$ GBT. Results are from single bottles for each treatment. The July 6 samples were collected from Mobile Bay and had a salinity of 16 psu and a temperature of $28^{\circ} \mathrm{C}$. The July 19 samples were collected from Fort Morgan Beach located just east of Mobile Bay on the Gulf of Mexico. Salinity was 28 psu and temperature was $28^{\circ} \mathrm{C}$

\section{Effects of DMSP analogs other than GBT}

$\beta$-Alanine betaine strongly inhibited net DMSP(d) consumption and DMS production with a $10 \mu \mathrm{M}$ addition being equally as effective as $50 \mu \mathrm{M}$ GBT (Fig. 3A). There was little net decrease $(<1 \mathrm{nM})$ of $\mathrm{DMSP}(\mathrm{d})$ in the presence of either GBT or $\beta$-alanine betaine over the first $7 \mathrm{~h}$ of the experiment, but about 3 to $4 \mathrm{nM}$ DMS accumulated during this period (Fig. 3B). DMS production in the absence of a net decrease DMSP(d) could have been due to direct production from the particulate pool or perhaps to enhanced turnover of DMSP(d) due to some release from the particulate pool.

In experiments similar to those presented in Figs. 1 \& 3, a variety of other low molecular weight organic compounds were tested for effects on net DMSP consumption in natural water samples (Table 2) Each 

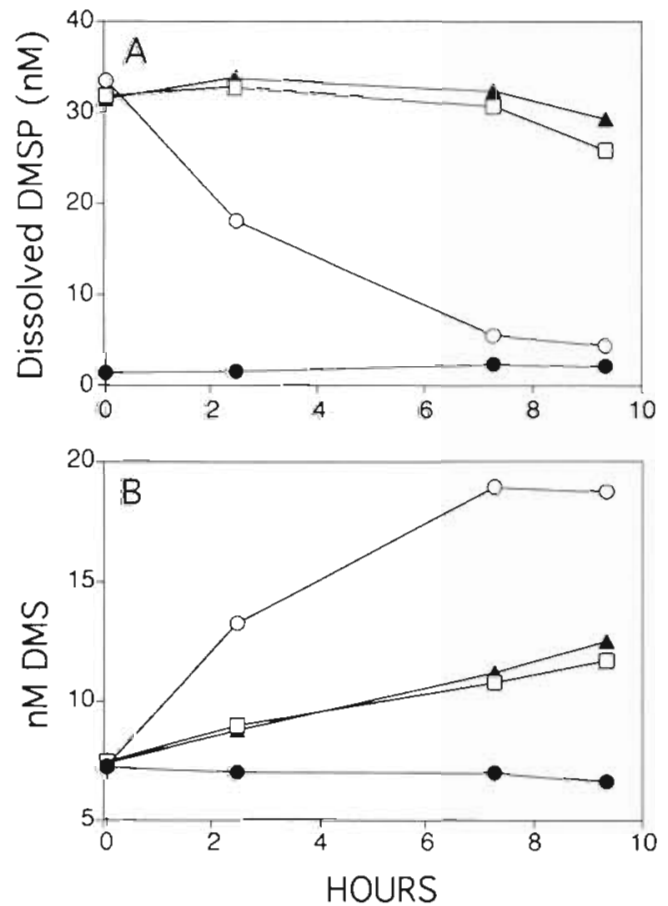

Fig. 3. Time courses of (A) DMSP(d) and (B) DMS concentrations in water samples from the Sea Buoy site after the following treatments: no addition $(\bullet)$; DMSP $(O)_{i}+\mathrm{DMSP}+10 \mu \mathrm{M}$

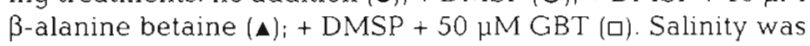
$35 \mathrm{psu}$ and temperature was $15.5^{\circ} \mathrm{C}$. Results are from single bottles for each treatment

experiment listed within Table 2 used a different batch of Mobile Bay water, therefore a GBT treatment was included in each experiment as a positive experimental control. Results for GBT-treated samples showed $>75 \%$ inhibition of net DMSP(d) consumption activity in all cases. In Expt 1 choline had no effect on DMSP(d) consumption while it slightly stimulated DMS production (Table 2). By comparison, dimethylglycine, carnitine and proline were moderately inhibitory to both DMSP degradation and DMS production (Table 2, Expt 1). DESP, a synthetic ethylated analog of DMSP, was inhibitory to DMSP(d) consumption at 1, 10 and $50 \mu \mathrm{M}$ concentrations (Table 2, Expt 2). DMS production, however, appeared to be stimulated by DESP in Expt 2, with $50 \mu \mathrm{M}$ DESP yielding the highest DMS production. In apparent contrast to these results, DESP was inhibitory to both DMSP(d) consumption and DMS production in Expt 3. The contrasting results for DMS production may have been due to a greater production of ethanethiol from DESP in Expt 2 but we were not able to distinguish ethanethiol from DMS on our chromatography system. Ethanethiol production from DESP would be analogous to the methanethiol production from DMSP which has recently been observed (Kiene unpubl.).
Natural water samples treated with DESP produced diethylsulfide (DES) indicating that DESP may be a substrate for DMSP lyase. We did not quantify the amount of DES formed due to a lack of an appropriate standard at the time

Choline-O-sulfate was not inhibitory to net DMSP(d) consumption at either 1 or $50 \mu \mathrm{M}$ (Table 2). DMS production was unaffected by the $50 \mu \mathrm{M}$ choline-O-sulfate but the $1 \mu \mathrm{M}$ treatment yielded $50 \%$ inhibition of DMS production. The anomalous inhibition of DMS production by $1 \mu \mathrm{M}$ choline-O-sulfate (no effect on DMSP degradation) may have been due to an atypically high variability in DMS production associated with this batch of water. This variability was probably caused by a rapid net accumulation of DMS in all the samples from this experiment including the non-DMSP treated controls (data not shown).

\section{Non-onium compound effects}

Several low molecular weight organic compounds including glucose, glutamic acid, glycine, and acrylic acid (each at $50 \mu \mathrm{M}$ ) had little effect on the net consumption of added DMSP(d) in water samples (Table 2 , Expt 5). By comparison, treatment with GBT clearly inhibited DMSP(d) consumption compared to the control with DMSP(d) alone, and actually caused a net increase in DMSP(d) over the $4.5 \mathrm{~h}$ experiment (translating to a $126 \%$ inhibition of DMSP degradation). The effects on DMS production followed a similar pattern, with GBT yielding $81 \%$ inhibition while glucose, glutamic acid, glycine and acrylic acid had no discernible inhibitory effects. The DMS production in the acrylic acid treatment was $21 \%$ higher than the DMSP-alone treatment.

\section{GBT causes DMSP to accumulate}

Having established that GBT strongly inhibited the consumption of added DMSP(d) in short-term experiments, we investigated whether GBT amendments had any effects on the endogenous pool of DMSP(d). We used $50 \mu \mathrm{M}$ GBT since this appeared to be $>80 \%$ effective over 5 to $6 \mathrm{~h}$ in all cases. The concentration of DMSP(d) increased significantly in water samples to which GBT was added (Fig. 4), and the rate of change was clearly distinguishable from that in the untreated samples. In most cases, GBT had no effects on DMS concentrations over 4 to $6 \mathrm{~h}$ but there was occasionally a slightly higher production of DMS in the later time points. This may have resulted from the higher DMSP(d) concentrations which had accumulated (Kiene \& Service 1993). 
Table 2. Effects of various low molecular weight organic compounds on degradation of exogenous DMSP(d) and production of DMS. Results are expressed as the percentage inhibition of DMSP degradation or DMS production defined as follows: [1 - (rate in experimental samples/rate in DMSP only samples)] $\times 100$. Negative values indicate stimulation of the activity while values greater than 100 indicate net accumulation of DMSP(d) rather than degradation. All water samples were collected from Mobile Bay

\begin{tabular}{|c|c|c|c|c|}
\hline \multirow{2}{*}{ Experiment } & \multirow{2}{*}{ Treatment compound } & \multicolumn{3}{|c|}{$\%$ Inhibition } \\
\hline & & $\begin{array}{l}\text { Concentration of } \\
\text { added DMSP }\end{array}$ & $\begin{array}{c}\text { DMSP(d) } \\
\text { degradation }\end{array}$ & $\begin{array}{l}\text { DMS } \\
\text { production }\end{array}$ \\
\hline \multicolumn{5}{|c|}{ Various onium compounds } \\
\hline \multirow[t]{5}{*}{1} & Glycine betaine & $50 \mu \mathrm{M}$ & 85 & 82 \\
\hline & Choline & $50 \mu \mathrm{M}$ & -2 & -21 \\
\hline & Dimethylglycine & $50 \mu \mathrm{M}$ & 66 & 49 \\
\hline & Carnitine & $50 \mu \mathrm{M}$ & 37 & 51 \\
\hline & Proline & $50 \mu \mathrm{M}$ & 55 & 43 \\
\hline \multirow[t]{4}{*}{2} & Glycine betaine & $50 \mu \mathrm{M}$ & 103 & 45 \\
\hline & Diethylsulfoniopropionate & $50 \mu \mathrm{M}$ & 62 & $-116^{\circ}$ \\
\hline & Diethylsulfoniopropionate & $10 \mu \mathrm{M}$ & 67 & $-39^{\circ}$ \\
\hline & Diethylsulfoniopropionate & $1 \mu \mathrm{M}$ & 54 & $-39^{*}$ \\
\hline \multirow[t]{4}{*}{3} & Glycine betaine & $50 \mu \mathrm{M}$ & 75 & 77 \\
\hline & Diethylsulfoniopropionate & $50 \mu \mathrm{M}$ & 86 & 66 \\
\hline & Diethylsulfoniopropionate & $10 \mu \mathrm{M}$ & 68 & 47 \\
\hline & Diethylsulfoniopropionate & $1 \mu \mathrm{M}$ & 21 & 32 \\
\hline \multirow[t]{3}{*}{4} & Glycine betaine & $50 \mu \mathrm{M}$ & 113 & 43 \\
\hline & Choline sulfate & $50 \mu \mathrm{M}$ & -12 & 3 \\
\hline & Choline sulfate & $1 \mu \mathrm{M}$ & -3 & 50 \\
\hline \multicolumn{5}{|c|}{ Non-onium compounds } \\
\hline \multirow[t]{5}{*}{5} & Glycine betaine & $50 \mu \mathrm{M}$ & 126 & 81 \\
\hline & Acrylic acid & $50 \mu \mathrm{M}$ & -10 & -21 \\
\hline & Glucose & $50 \mu \mathrm{M}$ & -2 & -3 \\
\hline & Glycine & $50 \mu \mathrm{M}$ & 0 & 5 \\
\hline & Glutamic acid & $50 \mu \mathrm{M}$ & -8 & -3 \\
\hline
\end{tabular}

We carried out a total of 11 experiments with natural water samples in which we added only $50 \mu \mathrm{M}$ GBT and found similar results to those in Fig. 4 in each. GBT amendments always caused a linear net increase in DMSP(d) relative to an untreated control over a 1 to $4 \mathrm{~h}$ period; however, the rate of this accumulation differed depending on the sampling date. When the initial accumulation rates are plotted against the in situ temperature a good correlation $\left(\mathrm{r}^{2}=0.958 ; \mathrm{n}=9\right)$ is obtained for most of the data (Fig. 5). Data from 2 experiments did not follow the trend and these both were summer samples from Mobile Bay with relatively high temperatures $\left(28^{\circ} \mathrm{C}\right)$. The reasons for these low accumulations are not presently clear No significant correlation was found between GBT-induced DMSP(d) accumulation rates and in situ DMSP(p) and DMSP(d) concentrations or salinity (data not shown).

In seawater samples treated with GBT, DMSP(d) accumulation slowed beyond $6 \mathrm{~h}$. In order to investigate this an experiment was carried out in which GBT was added at time zero, but also after $8 \mathrm{~h}$ (Fig. 6). Samples initially treated with GBT had a relatively rapid accumulation of DMSP(d) ( 4 nM d $\left.\mathrm{d}^{-1}\right)$ whereas the untreated samples had a fairly steady DMSP(d) concentration for about $7 \mathrm{~h}$. At $8 \mathrm{~h}$ into the experiment, 1 set of GBT-treated samples was retreated with $50 \mu \mathrm{M}$ GBT. At the same time, a previously untreated sample was spiked with GBT. The accumulation rate was nearly identical in the 2 cases over the 8 to 24 h time period $\left(1.73\right.$ and $\left.1.68 \mathrm{nM} \mathrm{d}^{-1}\right)$ and this rate was slower than that observed over the 0 to $8 \mathrm{~h}$ time period. We observed that in most cases the inhibitory effects of GBT diminished over time and the DMSP(d) which had accumulated in the presence of GBT started to decline after prolonged incubation. This was not evident in the experiment in Fig. 6, most likely due to the low incubation temperature $\left(8.5^{\circ} \mathrm{C}\right)$ and slow DMSP(d) turnover.

\section{GBT effects on particulate DMSP}

One possible explanation for the accumulation of DMSP(d) after the addition of GBT is a direct release of 

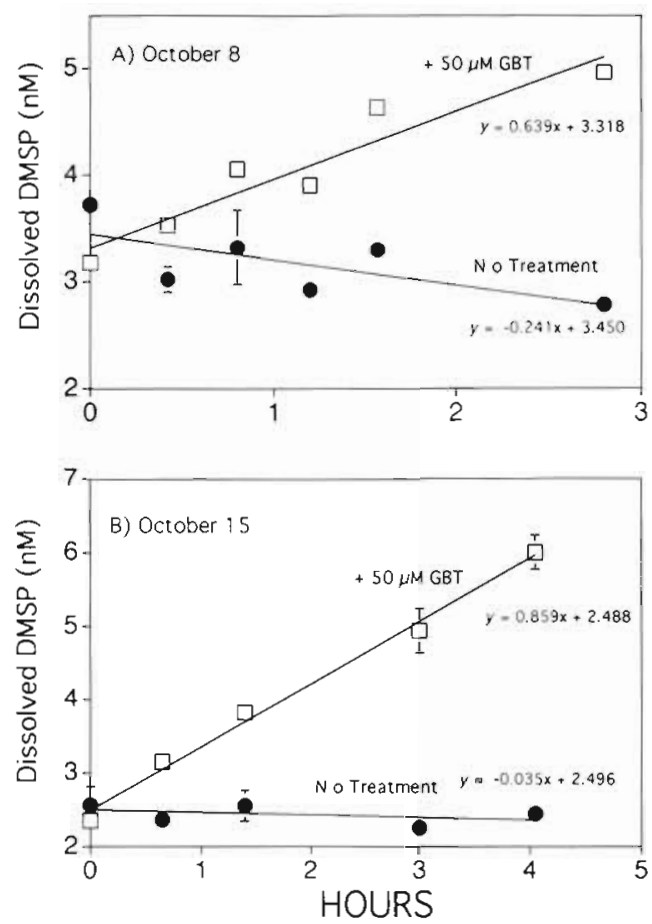

Fig. 4. Effects of $50 \mu \mathrm{M} \mathrm{GBT}$ on the endogenous concentrations of DMSP(d) in Mobile Bay water samples. Results from 2 separate experiments are shown (A, B, respectively). Data points represent the mean of duplicate bottles with the error bars indicating the range. Lack of visible error bars indicates a range smaller than the symbol. Lines are linear fits to the data with the equations shown. Incubation temperatures were 23 and $22^{\circ} \mathrm{C}$ and salinities were 26 and 28 psu for (A) and $(B)$, respectively

DMSP by phytoplankton or other organisms caused by the $50 \mu \mathrm{M}$ GBT addition. Several experiments were conducted to test whether GBT additions affected particulate DMSP concentrations (Fig. 7). Slightly lower DMSP $(p)$ concentrations were observed in the GBTtreated samples by the end of the experiment, but the results were not statistically significant $(p>0.05$, Student's $t$-test). When an axenic, DMSP-producing algal culture, Tetraselmis subcordiformis, was tested, about $20 \mathrm{nM}$ DMSP(d) accumulated in $1 \mathrm{~h}$ after GBT addition, and no increase occurred afterward (Fig. 8A). This represented a small ( $2 \%$ ) fraction of the total particulate DMSP (965 nM) in the culture. GBT had no significant effect on the particulate DMSP levels in the culture over the $6 \mathrm{~h}$ incubation (Fig. $8 \mathrm{~B}$ ).

\section{DISCUSSION}

The turnover of algal-derived DMSP in seawater is of interest because it is a labile component of dissolved organic matter and because DMSP is a precursor of volatile DMS. Relatively little is known about how

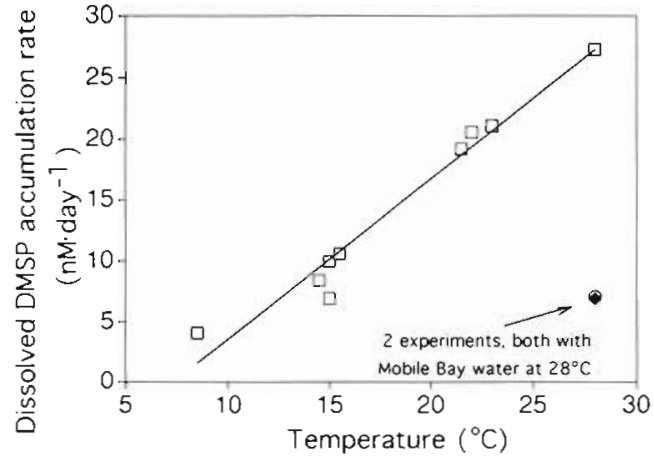

Fig. 5. Relationship between DMSP(d) accumulation rates caused by addition of $50 \mu \mathrm{M}$ GBT and the incubation temperature for experiments conducted from September 1993 to September 1994. Results from 2 experiments conducted at $28^{\circ} \mathrm{C}$ with Mobile Bay water fall off the trend and were not included in the regression line. The highest accumulation rate sample on the line was also at $28^{\circ} \mathrm{C}$, but this was from an incubation with shelf water collected at the Sea Buoy. Equation for the regression line: $y=1.338 x-9.91 ; r^{2}=0.958 ; n=9$

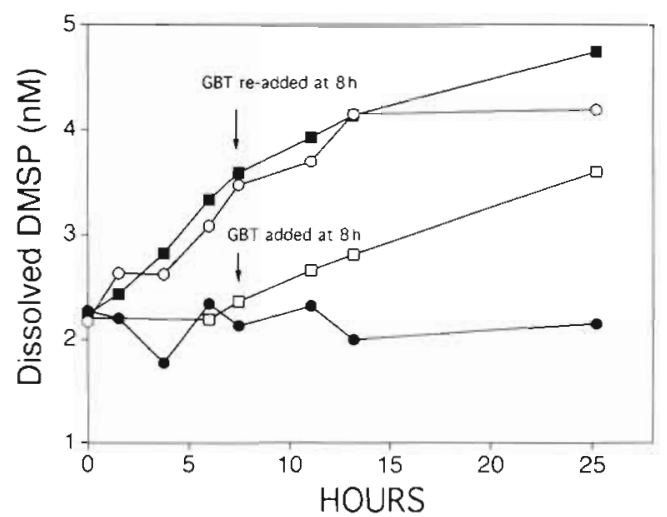

Fig. 6. Time course of DMSP(d) concentration in Mobile Bay water samples incubated with various additions as follows: no addition (•); $50 \mu \mathrm{M}$ GBT at time zero (o); $50 \mu \mathrm{M}$ GBT at $8 \mathrm{~h}$ (a); and $50 \mu \mathrm{M} \mathrm{GBT}$ at time zero and again at $8 \mathrm{~h}$ ( $\mathbf{m}$ ). Results are from single bottles for each treatment. Experiment was conducted in winter and the in situ temperature was $8.5^{\circ} \mathrm{C}$; salinity was 28 psu

DMSP is degraded in situ because it has been difficult to tease apart the complex interactions within the food web which are responsible for producing and consuming this compound. Specific inhibitors of biogeochemical processes are often useful at helping to elucidate how compounds are cycled in natural systems (Oremland \& Capone 1988), but previous studies have observed that the decomposition of DMSP in seawater is relatively insensitive to a variety of inhibitors (Kiene 1990). Here we found that treatment of seawater samples with 1 to 50 MM GBT strongly inhibited the degradation of DMSP(d) during short-term $(<6 \mathrm{~h})$ incubations. The higher concentrations of GBT tended to 

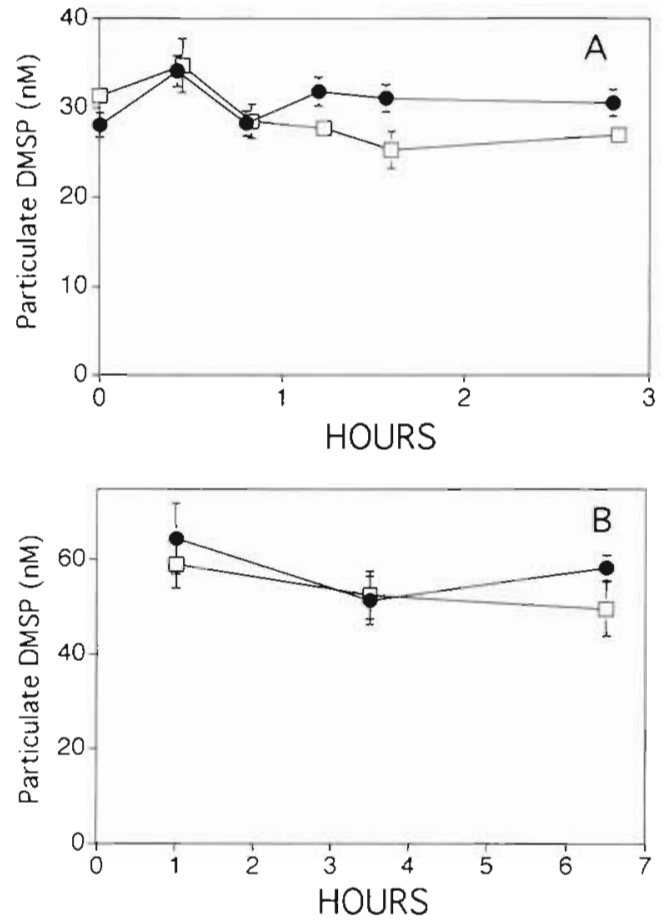

Fig 7. Effects of $50 \mu \mathrm{M}$ GBT on particulate DMSP concentration in water samples from 2 experiments using Mobile Bay water. (A) Data from October 8, 1994; points represent the mean of duplicate bottles (bars indicate range). (B) Data from November 2, 1994; points represent triplicates (bars indicating standard deviation). Treatments were: no addition $(\bullet)$ and $+50 \mu \mathrm{M}$ GBT (a). For the October 8 experiment, the salinity was 26 psu and the temperature was $23^{\circ} \mathrm{C}$. For the November 2 experiment, the salinity was 28 and the temperature was $14.5^{\circ} \mathrm{C}$. Samples were incubated in the dark for the duration of the experiment

have a longer lasting effect (Fig 1), although even $50 \mu \mathrm{M}$ lost effectiveness beyond $6 \mathrm{~h}$. In the absence of an inhibitor, DMSP(d) was degraded rapidly in the estuarine and coastal water samples used here and a portion of the consumed DMSP(d) was accounted for as DMS. The relatively low yield $(<50 \%)$ of DMS from DMSP(d) (Table 1) is consistent with previous studies (Kiene \& Service 1991, Kiene 1992) and is probably due to degradation of most of the DMSP by a demethylation pathway (Taylor \& Gilchrist 1991, Kiene 1993). GBT apparently inhibited both the lyase and demethylation pathways of DMSP degradation (Fig. 1B), but the exact mechanism(s) behind this inhibition remains to be elucidated.

Compounds which are chemically similar to GBT (and DMSP) including $\beta$-alanine betaine, diethylsulfoniopropionate, carnitine, proline, and dimethylglycine also inhibited DMSP(d) consumption and DMS production when added at 10 to $50 \mu \mathrm{M}$ concentrations (Fig. 3, Table 2). Each of these compounds (with the exception of dimethylglycine) has an onium functional
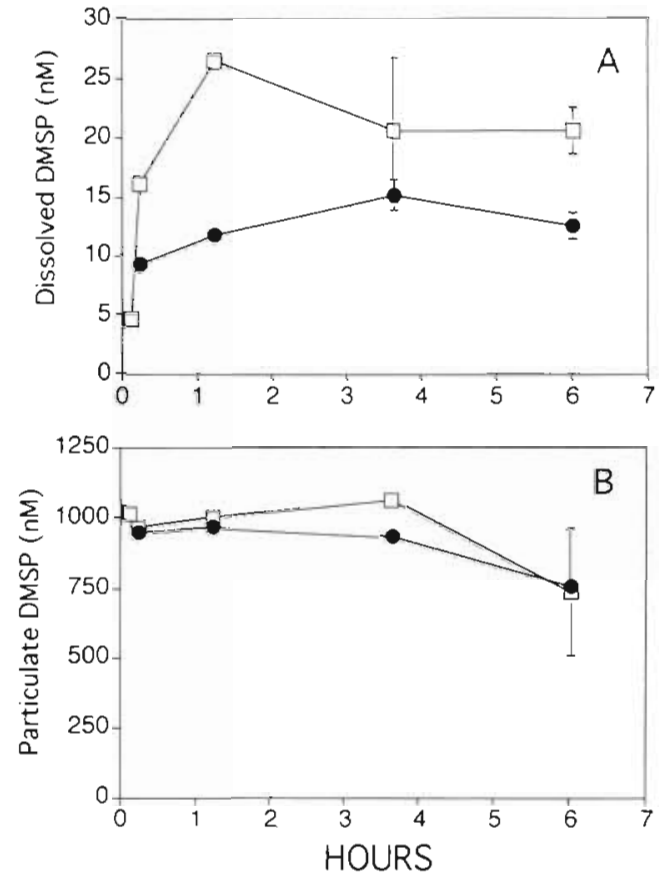

Fig. 8. Time courses of (A) DMSP(d) and (B) DMSP(p) concentrations in axenic cultures of the phytoplankter Tetraselmis subcordiformis. Treatments were: no addition (-) and $+50 \mu \mathrm{M}$ GBT (a). After GBT additions, cultures were incubated in the dark at room temperature $\left(21^{\circ} \mathrm{C}\right)$. Results are the mean of duplicate cultures with the error bars indicating the range

group (tertiary sulfonium or quaternary ammonium) in close proximity to a carboxyl group. In contrast, other low molecular weight organic compounds lacking the 'betaine' structure, including glycine, glucose, glutamic acid, acrylic acid, choline and choline sulfate had no substantial inhibitory effects on DMSP(d) degradation. These results suggest that GBT and the other related compounds may react with some enzyme system(s) involved in DMSP degradation.

We speculate that the inhibition of DMSP degradation caused by GBT and related analogs is due to a competitive blockage of the trans-membrane transport of DMSP to the site of the lyase or demethylating enzymes, rather than direct inhibition of the degradation enzymes. Little is known about the enzymology of DMSP demethylation; however, de Souza \& Yoch (1995) recently reported that a purified DMSP(d) lyase obtained from an estuarine Alcaligenes-like bacterium was not inhibited (nor induced) by GBT, dimethylglycine, dimethylsulfonioacetate, methionine, S-methylmethionine or several other low molecular weight compounds. Peroud \& LeRudulier (1985), on the other hand, found that GBT transport into Escherichia coli cells was inhibited by several betaine analogs, including dimethylglycine, proline and $\beta$-alanine betaine, 
each of which inhibited DMSP degradation in seawater (Fig. 3, Table 2). Given this evidence, it seems likely that a DMSP transport system might recognize GBT (and vice versa). This is known to be the case in the Enterobacteriaceae (Chambers et al. 1987). Such a transport mechanism could be useful to marine microorganisms since both DMSP and GBT are natural compounds and could be used as a sources of carbon as well as nitrogen in the case of GBT.

We observed that GBT slightly enhanced the yield of DMS (Table 1) during short-term experiments and that GBT was generally less inhibitory to DMS production as compared to net DMSP(d) consumption (Fig. 3, Table 2). GBT is a substrate for some DMSP-demethylating bacteria (Visscher \& Taylor 1994); therefore, high concentrations of GBT could possibly overwhelm the demethylation pathway and allow more DMSP to be degraded by the lyase pathway. This explanation is consistent with the fact that GBT additions alone often stimulate DMS production (Kiene \& Service 1993).

The degradation of DMSP(d) in Mobile Bay water is primarily due to bacteria-sized $(<1.0 \mu \mathrm{m})$ organisms (Kiene in press), therefore GBT probably acts upon the bacterial degradation of DMSP. Recently, it has been reported that phytoplankton and perhaps microzooplankton are able to degrade DMSP(d) (Stefels \& van Boekel 1993, Wolfe et al. 1994). Wolfe et al. (1994) found that GBT had no effects on DMSP pools in a mixed bacteria, phytoplankter and ciliate culture, nor on rates of DMSP degradation in a pure bacterial isolate. Further work will be necessary to test whether GBT affects some organisms but not others. In the present study, the inhibitory effects of GBT on DMSP(d) net consumption and DMS production were observed in waters collected from a variety of locales including inshore waters from Mobile Bay (Figs. 1 \& 2), shelf waters $10 \mathrm{~km}$ out in the Gulf of Mexico (Fig. 3) and in temperate waters from Great Bay, New Hampshire, USA (R. Kiene unpubl.). In addition, GBT inhibited DMSP(d) degradation in estuarine waters from Georgia, USA (Kiene \& Service 1993). These findings suggest that the phenomenon we observed is characteristic of many coastal and shelf waters.

The effectiveness of GBT diminished over time for reasons which are not yet clear. This could have been caused by degradation of the GBT or by adaptation and growth of the microbial populations. It is possible, but not likely, that a large proportion of the $50 \mu \mathrm{M}$ added GBT was degraded during the 6 h experiments. Unfortunately we are not able to measure these levels of GBT in seawater solutions to determine if GBT was substantially degraded. Experiments in which we respiked $50 \mu \mathrm{M}$ GBT after 6 to $8 \mathrm{~h}$ did not indicate a resumption of inhibition (Fig. 6). It therefore seems more likely that microbial populations adapt to the high levels of GBT, by growing and possibly by synthesizing a transport system which also may recognize DMSP. The increased putative transport of DMSP into bacterial cells may allow degradation to resume.

Since $50 \mu \mathrm{M}$ GBT was clearly inhibitory to DMSP(d) degradation for at least 4 to $6 \mathrm{~h}$, the initial accumulation rates of DMSP(d) in the presence of GBT (Fig. 4) might represent the natural turnover (production in the absence of consumption) of the dissolved DMSP(d) pool. For the accumulation rates to be a valid representation of the DMSP(d) turnover, GBT must not cause particulate DMSP to be released into the DMSP(d) pool faster than would occur by natural release mechanisms (leaching, grazing, etc.). In many of the experiments that we carried out, GBT-treated samples had slightly lower DMSP(p) than controls. However, when this was examined more closely with replication of the treatments (Fig. 7), no statistically significant effects of GBT on the particulate pools were observed. We emphasize that these results apply only to our short duration, dark incubations (i.e. Figs. $7 \& 8$ ). In the light and over longer periods, GBT can have significant effects on phytoplankton DMSP production (Kiene \& Service 1993). It should be noted that a small, perhaps insignificant, decrease in DMSP(p) might be enough to significantly increase the DMSP(d) pool since the particulate DMSP concentrations in natural water samples of Mobile Bay are often >10- to 20 -fold higher than dissolved DMSP. The results from the phytoplankton culture experiment (Fig. 8) suggest that only a small fraction ( 2\%) of the phytoplankton DMSP(p) may be released as DMSP(d) as a result of the GBT addition. Applying this percentage to natural water samples with 30 to $60 \mathrm{nM}$ DMSP(p) would give a potential release of 0.6 to $1.2 \mathrm{nM}$ DMSP(d). This amount is comparable but somewhat less than the accumulations that were typically observed in 4 to $6 \mathrm{~h}$ experiments (Fig. 4).

If we conclude that the accumulation of DMSP(d) was an artifact of the GBT addition, then we must conclude that DMSP(d) turnover was very slow. This does not appear to be a reasonable conclusion given the rapid first order consumption of added DMSP(d) that was observed. The DMSP(d) turnover rates, calculated from the pseudo-first order rate constants (obtained from loss curves) and the in situ concentration, ranged from 2 to $122 \mathrm{nM} \mathrm{d}^{-1}$ during the period of the present study (Kiene in press). The GBT-determined rates ranged from 4 to $27 \mathrm{nM} \mathrm{d} \mathrm{d}^{-1}$ and tended to be lower than the consumption-based rates when direct comparisons were made with the same water samples (data not shown). We cannot draw firm conclusions at this time as to which technique yields the correct turnover rates. Further work will be necessary to resolve this issue. 
Our results with GBT and its analogs give us clues as to the mechanism(s) of DMSP degradation in seawater, a subject about which little is currently known. DMSP degradation appears to depend on an uptake and/or degradation system which is not strictly specific for DMSP, but rather for betaine-like compounds. This raises the possibility that under natural circumstances, DMSP and GBT might be metabolized similarly and that degradation of either compound might be influenced by high concentrations of the other. Based on the limited information in the literature, we suggest that the transport system is the most likely site of the inhibition by GBT (c.f. Peroud \& LeRudulier 1985, de Souza \& Yoch 1995). With the knowledge gained here about the specificity of the inhibition for betaine-like compounds, we can propose that more effective inhibitors than GBT might be found by using synthetic analogs or those with substitutions which make them more inhibitory than their natural counterparts. $\beta$-Alanine betaine appeared to be an excellent inhibitor with $10 \mu \mathrm{M}$ being equally as effective as $50 \mu \mathrm{M}$ GBT. Our supply of $\beta$-alanine betaine was limited; therefore, we could not test this compound in detail. Peroud \& LeRudulier (1985) found that of the compounds they tested, proline betaine (stachydrine) was the most effective inhibitor of GBT transport in Escherichia coli. Such compounds could prove useful in future studies.

\section{CONCLUSION}

GBT was an effective inhibitor of DMSP(d) degradation in short term $(<6$ h) experiments with natural water samples. A variety of chemically similar onium compounds were also found to be inhibitory, whereas non-onium compounds were not. GBT may be a useful inhibitor of DMSP(d) degradation (and DMS production) for biogeochemical studies and might possibly enable DMSP(d) turnover rates to be determined. However, the short-lived inhibitory effects of GBT in coastal waters may limit its application to very short-term experiments. Furthermore, lack of agreement between DMSP(d) turnover rates calculated from GBT inhibition experiments and those from kinetically derived rate constants suggests caution should be used when applying GBT (or related inhibitors). Additional work will be needed to determine whether GBT has less or more effectiveness in other types of waters, especially oceanic waters. The results of this study have shed light on the mechanisms responsible for degrading $\mathrm{DMSP}(\mathrm{d})$ in coastal and estuarine waters and suggest that a multifunctional trans-membrane transport system might be involved.
Acknowledgements. We offer special thanks to Andrew Hanson for providing us with $\beta$-alanine betaine and choline sulfate and to Barrie Taylor for providing us with DESP. We also thank Duane Yoch for sharing a preprint. We gratefully acknowledge Lynn Hoffmann and Brian Jones who provided help in the lab. Support for this research was provided by NSF Grants OCE-92-03728 and OCE-9218511

\section{LITERATURE CITED}

Ackman RG, Hingley HJ (1968) The occurrence and retention of dimethyl- $\beta$-propiothetin in some filter-feeding organisms. J Fish Res Bd Can 25:267-284

Andreae MO (1990) Ocean-atmosphere interactions in the global biogeochemical sulfur cycle. Mar Chem 30:1-29

Andreae MO, Raemdonck $H$ (1983) Dimethyl sulfide in the surface ocean and the marine atmosphere: a global view. Science 221:744-747

Bates IS. Charlson RJ, Gammon RH (1987) Evidence for the climatic role of marine biogenic sulphur. Nature 329 : $319-321$

Bates TS, Kiene RP, Wolfe GV, Matrai PA, Chavez FP, Buck KR, Blomquist BW, Cuhel RL (1994) The cycling of sulfur in surface sea water of the Northeast Pacific. J geophys Res - Oceans 99:7835-7843

Belviso S, Kim SK, Rassoulzadegan F, Krajka B, Nguyen BC, Mihalopoulos N, Buat-Menard P (1990) Production of dimethylsulfonium propionate (DMSP) and dimethylsulfide (DMS) by a microbial food web. Limnol Oceanogr 35 : $1810-1821$

Burgermeister S, Zimmermann RL, Georgii HW, Bingemer HG, Kirst GO, Janssen M, Ernst W (1990) On the biogenic origin of dimethylsulfide: relation between chlorophyll, ATP, organismic DMSP, phytoplankton species, and DMS distribution in Atlantic surface water and atmosphere. $\mathrm{J}$ geophys Res 95:20607-20615

Chambers ST, Kunin CM, Miller D, Hamada A (1987) Dimethylthetin can substitute for glycine betaine as a osmoprotectant molecule for Escherichia coli. J Bacteriol 169:4845-4847

Charlson RJ, Lovelock JE, Andreae MO, Warren SG (1987) Oceanic phytoplankton, atmospheric sulfur, cloud albedo and climate. Nature 326:655-661

Dacey JWH, Wakeham SG (1986) Oceanic dimethylsulfide production during zooplankton grazing on phytoplankton Science 233:1314-1316

de Souza MP, Yoch DC (1995) Purification and characterization of DMSP lyase from an Alcaligenes-like dimethylsulfide-producing marine isolate. Appl environ Microbiol 61 $21-26$

Dlaz MR, Visscher PT, Taylor BF (1992) Metabolism of dimethylsulfoniopropionate and glycine betaıne by a marine bacterium. FEMS Microbıol Lett 96:61-66

Gabric A, Murray N, Stone L, Kohl M (1993) Modelling the production of dimethylsulfide during a phytoplankton bloom. J geophys Res 98:22805-22816

Iida H, Nakazoe J, Saito H, Tokunaga T (1986) Effect of diet on dimethyl-B-propiothetin content in fish. Bull Jap Soc scient Fish 52:2155-2161

Iida H, Tokunaga T (1986) Dimethyl sulfide and dimethyl-Bpropiothetin in shellfish. Bull Jap Soc scient Fish 52: $557-563$

Iverson RL, Nearhoof FL, Andreae MO (1989) Production of dimethylsulfonium propionate and dimethylsulfide by phytoplankton in estuarine and coastal waters. Limnol Oceanogr 34:53-67 
Keller MD (1991) Dimethyl sulfide production and marine phytoplankton: the importance of species composition and cell size. Biol Oceanogr 6:375-382

Keller MD, Bellows WK, Guillard RRL (1989) Dimethyl sulfide production in marine phytoplankton. In: Saltzman $E$, Cooper WJ (eds) Biogenic sulfur in the environment. Am Chemical Soc, New York, p 167-182

Kiene RP (1990) Dimethyl sulfide production from dimethylsulfoniopropionate in coastal seawater samples and bacterial cultures. Appl environ Microbiol 56:3292-3297

Kiene RP (1992) Dynamics of dimethyl sulfide and dimethylsulfoniopropionate in oceanic seawater samples. Mar Chem 37:29-52

Kiene RP (1993) Microbial sources and sinks for methylated sulfur compounds in the marine environment. In: Kelly DP, Murrell JC (eds) Microbial growth on $C_{1}$ compounds, 7 . Intercept, London, p 15-33

Kiene RP (in press) Turnover of dissolved DMSP in estuarine and shelf waters of the Northern Gulf of Mexico. In: Kiene RP, Trisscher P, Keller MD, Kirst GO (eds) Biological and environmental chemistry of DMSP and related sulfonium compounds. Plenum, New York

Kiene RP, Gerard G (1994) Determination of trace levels of dimethylsulfoxide (DMSO) in sea water and rainwater. Mar Chem 47:1-12

Kiene RP, Service SK (1991) Decomposition of dissolved DMSP and DMS in estuarine waters: dependence on temperature and substrate concentration. Mar Ecol Prog Ser $76: 1-11$

Kiene RP, Service SK (1993) The influence of glycine betaine on dimethyl sulfide and dimethylsulfoniopropionate concentrations in seawater. In: Oremland RS (ed) The biogeochemistry of global change: radiatively important trace gases. Chapman and Hall, New York, p 654-671

King GM (1988) Distribution and metabolism of quaternary amines in marine sediments. In: Blackburn TH, Sorensen $J$ (eds) Nitrogen cycling in coastal marine environments. John Wiley, New York, p 143-173

Ledyard KM, Dacey JWH (1994) Dimethylsulfide production from dimethylsulfoniopropionate by a marine bacterium. Mar Ecol Prog Ser 110:95-103

Levasseur M, Keller MD, Bonneau E, D'Amours D, Bellows WK (1994) Oceanographic basis of a DMS-related Atlantic

This article was submitted to the editor cod (Gadus morhua) fishery problem: blackberry feed. Can J Fish Aquat Sci 51:881-889

Lovelock JE, Maggs RJ, Rasmussen RA (1972) Atmospheric dimethyl sulfide and the natural sulfur cycle. Nature 237 $452-453$

Malin G, Turner SM, Liss PS (1992) Sulfur: the plankton/ climate connection. J Phycol 28:590-597

Matrai PA, Keller MD (1994) Total organic sulfur and dimethylsulfoniopropionate (DMSP) in marine phytoplankton: intracellular variations. Mar Biol 119:61-68

Oremland RS, Capone DG (1988) Use of 'specific' inhibitors in biogeochemistry and microbial ecology. Adv microb Ecol 10:285-283

Peroud B, LeRudulier D (1985) Glycine betaine transport in Escherichia coli: osmotic modulation. J Bacteriol 161. $393-401$

Reed RH (1983) Measurement and osmotic significance of B-dimethylsulfoniopropionate in marine macroalgae. Mar Biol Lett 4:173-181

Stefels J, van Boekel WHM (1993) Production of DMS from dissolved DMSP in axenic cultures of the marine phytoplankton species Phaeocystis sp. Mar Ecol Prog Ser 97: $11-18$

Taylor BF, Gilchrist DC (1991) New routes for aerobic biodegradation of dimethylsulfoniopropionate. Appl environ Microbiol 57:3581-3584

Tokunaga T, Iida H, Nakamura K (1977) Formation of dimethyl sulfide in Antarctic krill, Euphausia superba. Bull Jap Soc scient Fish 43:1209-1217

Turner SM, Malin G, Liss PS (1988) The seasonal variation of dimethyl sulfide and dimethylsulfoniopropionate concentrations in nearshore waters. Limnol Oceanogr 33:364-375

Visscher PT, Diaz MR, Taylor BF (1992) Enumeration of bacteria which cleave or demethylate dimethylsulfoniopropionate in the Caribbean Sea. Mar Ecol Prog Ser 89:293-296

Visscher PT, Taylor BF (1994) Demethylation of dimethylsulfoniopropionate to 3-mercaptopropionate by an aerobic marine bacterium. Appl environ Microbiol 60:4617-4619

White RH (1982) Analysis of dimethyl sulfonium compounds in marine algae. $J$ mar Res 40:529-535

Wolfe GV, Sherr EB, Sherr BF (1994) Release and consumption of DMSP from Emiliania huxleyi during grazing by Oxyrrhis marina. Mar Ecol Prog Ser 111:111-119

Manuscript first received: December 27, 1994

Revised version accepted: May 9, 1995 